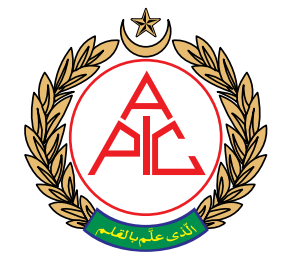

Healthcare

"Bobruisk

Oncologic

E-mail: varera@tut.by

${ }^{2}$ Healthcare Institution "Mogilev

Regional Hospital", 212026,

Mogilev, Republic of Belarus;

E-mail:marochkov@mail.ru

Correspondence:

Valery Yaskevich, anesthesiologist-resuscitator at the Anesthesiology and Intensive Care Department of the Healthcare Institution "Bobruisk Interdistrict Oncologic Dispensary", 213825, Bobruisk, Republic of Belarus, per.Sosnovy 40; email: varera@tut.by

E-mail: varera@tut.by

Phone: +375 296019421

Received: 22 September 2029

Reviewed: 10 February 2020

Revised: 5 March 2020

Accepted: 5 March 2020

\section{Comparative area of desensitiztion by three different volumes of local anesthetic solution for paravertebral block}

\author{
Valery Yaskevich ${ }^{1}$, Alexey Marochkov²
}

\section{ABSTRACT}

Aim and objectives: Ropivacaine is the drug of choice when we need more sensory block and less motor block. It also has a good safety margin. The anesthesiologists have been using rough formulas to determine the volume of the drug for the desired spread.

We conducted this study to determine the area distribution of paravertebral block (PVB) using three different volumes of ropivacaine.

Methodology: In this prospective observational study, eighty cases of breast cancer patients scheduled for mastectomy who had PVB were analyzed. The PVB was performed at levels T1 to T6. The patients were divided into three groups to receive 2.5 to $3.0 \mathrm{~mL}, 2.0 \mathrm{~mL}$, or $1.5 \mathrm{~mL}$ of $0.75 \%$ ropivacaine solution at each level (T1 to T6). The area of sensory block was determined by the pin prick method along the topographic thoracic lines (paravertebral, scapular, posterior axillary, midaxillary, midclavicular, and sternal lines). The resulting distances were measured using a centimeter ruler.

Results: Following the spinal nerve blocks (T1 to T6), the measured sensory block extents were as follows: 21.5 to $22.5 \mathrm{~cm}$ along the paravertebral line, 19.5 to $21.0 \mathrm{~cm}$ along the scapular line, 14.5 to $16.0 \mathrm{~cm}$ along the posterior axillary line, 14.0 to $15.0 \mathrm{~cm}$ along the midaxillary line, 12.5 to $14.0 \mathrm{~cm}$ along the midclavicular line, and 5.5 to $7.0 \mathrm{~cm}$ along the sternal line.

Conclusion: The three groups receiving different volumes of local anesthetic did not differ significantly in the area of loss of pain sensation along the same topographic thoracic lines.

Key words: Modified radical mastectomy; Ultrasound-guided; Nerve block; Paravertebral block.

Citation: Yaskevich V, Marochkov A. Comparative area of desensitiztion by three different volumes of local anesthetic solution for paravertebral block. Anaesth. pain intensive care 2020;24(2): 189-195

DOI: https://doi.org/10.35975/apic.v24i2.1255

\section{INTRODUCTION}

The benefits of regional blocks identified during the recent decades give a reason for the increased interest in the use of paravertebral block (PVB) in breast surgery. ${ }^{1}$ In PVB, a local anesthetic (LA) is injected into the paravertebral space along the spine at the required level. This results in a motor, sensory, and sympathetic block on the side of the block since the spinal nerves and sympathetic chain are located in the paravertebral space.

PVP is performed on the side of the surgical procedure using a single-injection or multiinjection technique, and it is also possible to install a catheter. ${ }^{1,2}$ In single injection PVB, 15 to $25 \mathrm{~mL}$ of LA is injected, whereas in a multiinjection PVB, 3.0 to $6.0 \mathrm{~mL}$ of LA is used for each nerve being blocked. ${ }^{2}$ The pattern of LA 
distribution in the paravertebral space is unpredictable. ${ }^{3,4,5}$ The number of the nerves being blocked when performing single injection PVB and injecting large LA volumes cannot be predetermined. The use of thoracic PVB in the thoracic surgery and breast surgery has been described in a number of publications, but the authors of these publications report that the PVB challenges remain intractable despite the use of electrical neurostimulation and ultrasound imaging. ${ }^{6,7}$ These publications provide no data on the objective monitoring of the sensory block development in the surgical intervention area upon the PVB.

To date, no sufficiently compelling clinical and anatomical justification has been provided of the efficacy of spinal nerve blocks across the surface of the thorax. ${ }^{8}$ Based on analysis of the available information, we have suggested that the features of the nerve trunk formation in the thoracic spine have a significant impact on the high frequency of the lack of efficacy in thoracic PVB.

We hypothesized that for multi-injection thoracic PVB, LA volumes of less than $3.0 \mathrm{ml}$ per nerve can be effectively used. A search of PubMed retrieved no publications describing the distribution of multi-injection thoracic PVB using LA dose of up to $3.0 \mathrm{ml}$ per nerve.

We conducted this study to determine extent of distribution of paravertebral block using different volumes of ropivacaine.

\section{METHODOLOGY}

This prospective observational study was approved by the Ethics Committee (Minutes No. 14 dated December 9, 2016). The observational data for the period from 15 December 2016 to 15 August 2019 is provided. An informed consent was obtained from the patients to be enrolled in the study and to undergo anesthesia. All patients required breast surgery with anesthetic support.

Inclusion criteria: Female, age $\geq 18$ years, breast surgery, availability of a written informed consent for anesthesia.
Exclusion criteria: Patient refusal regarding the type of anesthesia proposed, history of allergic reactions to the drug products to be used, skin infections at the site of the block as well as failure to cooperate with the patient.

This observational study analyzed eighty cases of upper thoracic PVB in breast cancer patients. The median age of the patients was $61.5 \mathrm{y}$ (range $55.0-68.8 \mathrm{y}$ ); median body weight was $77 \mathrm{~kg}$ (range $68-88 \mathrm{~kg}$ ), and the median height was $160.5 \mathrm{~cm}$ (range $157-164 \mathrm{~cm}$ ) .

The upper thoracic PVB was performed for anesthetic management of radical mastectomy and breast-conserving surgery in 70 and 10 cases, respectively.

The block was performed on the right side in 42 $(52 \%)$ cases and on the left side in $38(48 \%)$ cases.

The study end-point was the distance between the cranial and caudal borders of loss of pain sensation on the thoracic surface along the six topographic lines $20 \mathrm{~min}$ after PVB, determined by the pin prick method prior to general anesthesia.

The patients were divided into three groups depending on the volume of $0.75 \%$ ropivacaine solution used;

- Group 1 - PVB (T1 to T6) was performed using $1.5 \mathrm{~mL}$ per each nerve $(\mathrm{n}=44)$,

- Group $2-2.0 \mathrm{~mL}$ per each nerve $(\mathrm{n}=20)$, and

- Group 3 - 2.5-3.0 $\mathrm{mL}$ per each nerve $(\mathrm{n}=$ 16).

No differences were seen between the patients in these groups in terms of age, height, and body weight (Kruskal-Wallis test, $\mathrm{p}>0.05$ ). Table 1 shows the data obtained. All patients received premedication as follows: $7.5 \mathrm{mg}$ of zopiclone orally the day before the surgery as well as 0.5 $\mathrm{mg}$ of atropine and $10 \mathrm{mg}$ of diphenhydramine intramuscularly $30 \mathrm{~min}$ before the surgery. Upon admission to the operating room, a peripheral venous catheter was inserted and a monitoring system attached. The paravertebral block of the spinal nerves in the upper thoracic spine was performed as follows. The patient 
Table 1: Parameters and comparison of the groups receiving different LA volumes for PVB

\begin{tabular}{lcccc} 
Parameters & $\begin{array}{c}\text { Group 1 } \\
(\mathbf{n = 4 4 )}\end{array}$ & $\begin{array}{c}\text { Group 2 } \\
(\mathbf{n = 2 0 )}\end{array}$ & $\begin{array}{c}\text { Group 3 } \\
(\mathbf{n = 1 6 )}\end{array}$ & $\mathbf{p}$ \\
\hline Age $(\mathrm{y})$ & $\begin{array}{c}64.0 \\
(57.3-72.0)\end{array}$ & $\begin{array}{c}58.0 \\
(52.5-65.3)\end{array}$ & $\begin{array}{c}57.0 \\
(51.0-67.3)\end{array}$ & 0.168 \\
\hline Height (cm) & 160.0 & 161.5 & 161.0 & 0.371 \\
\hline Body wt & $(157.3-164.8)$ & $(154.5-164.3)$ & $(158.8-164.0)$ & \\
\hline kg) & 77.0 & 71.3 & 84.5 & 0.232 \\
\hline
\end{tabular}

Remarks: The Kruskal-Wallis test was used for statistical analysis.

Data given as Median (Range)

was sitting on the operating table. An antiseptic solution was

used on the skin. For pain management during the procedure, skin and subcutaneous tissue were infiltrated with 6 to $8 \mathrm{~mL}$ of $1 \%$ lidocaine the LA Quincke needles (Greatcare Medical Instruments more laterally from the spinous processes of the vertebrae on the side of the block.

Upon verification of the sonographic profile of paravertebral space at administration, the

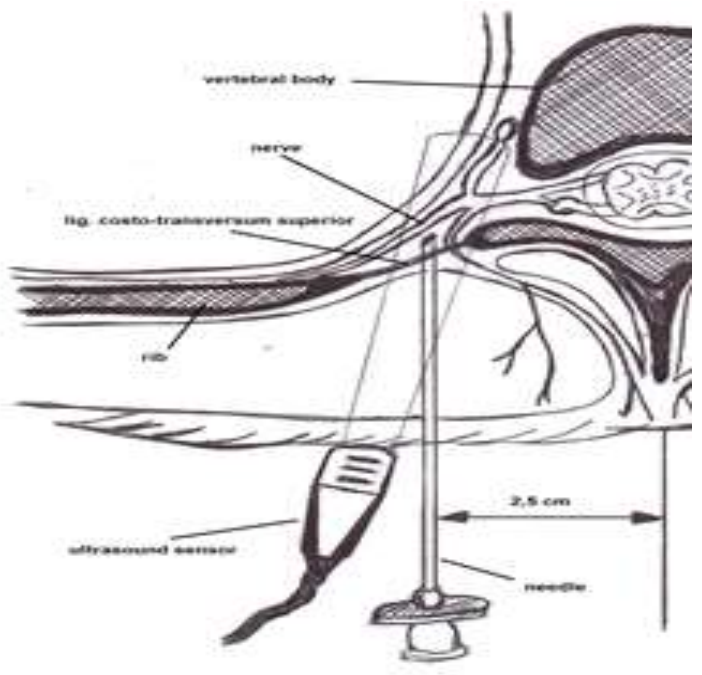

1-a ultrasound imaging was applied using HITACHI EUB-405 (Hitachi Medical Corporation, Tokyo, Japan) with a 7.5 $\mathrm{MHz}$ linear probe; and $90 \mathrm{~mm}$ long 22-23GCo., Ltd., Ningbo, China) were used for the solution along the paravertebral line, $2.5 \mathrm{~cm}$ To verify the position of a needle and to monitor levels $\mathrm{T} 1$, $\mathrm{T} 2, \mathrm{~T} 3, \mathrm{~T} 4, \mathrm{~T} 5$, and $\mathrm{T} 6$ on the monitor, an injection needle was inserted into the tissue using the out-of-plane ultrasound guidance until the tip of the needle reached the paravertebral space at the desired level (Figure $1)$.

Following the aspiration, $0.5 \mathrm{~mL}$ of $0.75 \%$ ropivacaine solution was injected with ultrasound monitoring of LA distribution in the paravertebral space, and then, upon repeated aspiration, $0.75 \%$ ropivacaine solution was additionally injected in an estimated volume.

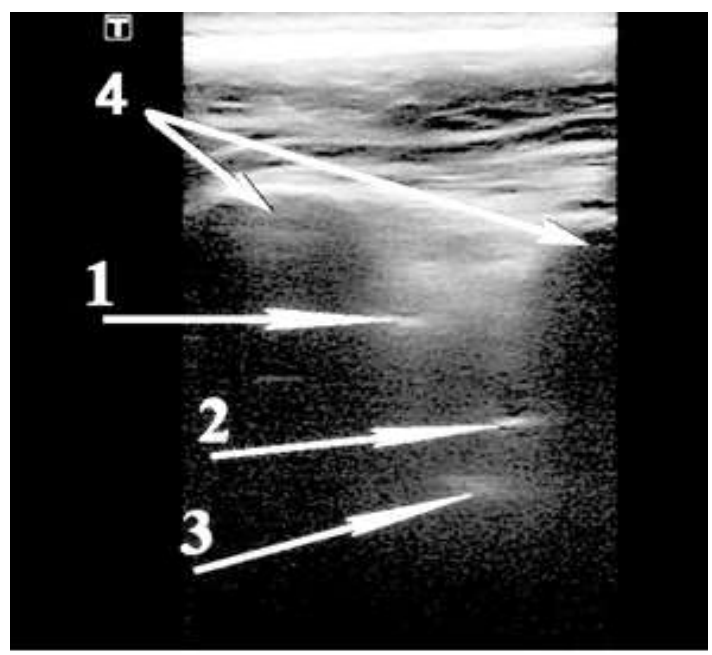

1-b

Figure 1: Schematic view of the US-guided upper thoracic paravertebral block (1-a) and ultrasound imaging of the out-of-plane upper thoracic paravertebral block (1-b)

(Key: 1 - superior costotransverse ligament, 2 - tip of the needle, 3 -parietal pleura, 4-transverse processes) 
After the block, an aseptic dressing was applied at the injection site, and the patient was put on the operating table in a supine position; and 20 min after the block, the loss of pain sensation on the thoracic surface was assessed using the pin prick method by using the following scale:

$[++]=$ complete loss of pain sensation (anesthesia),

$[+]=$ incomplete sensory block (the patient is unable to differentiate between the types of stimuli), and

$[-]=$ skin sensation is fully intact (no block).

The proximal (cranial) and distal (caudal) borders between the skin areas with altered pain sensation (+ and ++ ) and fully intact pain sensation ('-') were marked with a marker pen. The distances between the marked cranial and caudal borders were measured using a centimeter ruler along the six topographic thoracic lines:

1. Left and right parasternal lines - at the edges of the sternum.

2. Left and right midclavicular lines - through the midpoints of the clavicles.

3. Left and right midaxillary lines - halfway across the distance between the anterior and posterior axillary lines;

4. Left and right posterior axillary lines - from the posterior edges of the axillae.

5. Left and right subscapular lines - through the lower corners of the shoulder blades.

6. Left and right paravertebral lines - at the level of the transverse processes.

In radical mastectomy, the general anesthesia was, thereafter, provided.

Based on initial data, we calculated the minimum sample size required to deem the differences between the distances along the topographic thoracic lines significant. It amounted to nine patients per group. The accepted significance level is $5 \%$, and the power is $80 \%$. The clinically significant difference between the group means for sternal lines and midclavicular lines is $5.3 \mathrm{~cm}$, and the total SD is 3.86 .

Statistical analysis: Statistical analysis was performed using StatPlus Pro v6.5.0.0.
(AnalystSoft Inc., Walnut, CA, USA) and LibreOffice 5.0 (Free Software Foundation, Inc., OpenOffice.org). To evaluate the distribution, ShapiroWilk test was used. Median and 25th and 75th quartiles were calculated. When testing the significance of differences for dependent samples, the Wilcoxon test (comparison of two groups) and Friedman rank ANOVA (analysis of variance) (three groups or more) were used. To compare independent groups, the Mann-Whitney test (two groups) and the Kruskal-Wallis test (three groups or more) were used. The differences between the groups were considered statistically significant at $\mathrm{p}<0.05$. To overcome the problem of multiple comparisons, the Bonferroni correction was applied. For this, the significance level $\mathrm{p}$ was recalculated for multiple pairwise comparisons using the formula $\mathrm{p}_{0} / \mathrm{n}$, where $\mathrm{p}_{0}$ is the initially specified level of statistical significance (0.05), $\mathrm{n}$ is the number of pairwise comparisons.

\section{RESULTS}

Patients in the three groups were equivalent as regards to age, height and weight with no statistical difference (Table 1).

All patients underwent successful surgeries. No complications of anesthesia were reported. Pneumothorax was ruled out radiologically in all patients.

The study showed that after the spinal nerve block (T1 to T6) using different LA volumes per spinal nerve, different levels of the sensory block were seen at different measurements, but the readings were almost equivalent for the three volumes for each specific measurement along topographic thoracic lines (Table 2).

ANOVA for Groups 1, 2, and 3 showed the differences between the distances along the topographic thoracic lines (ANOVA, p < 0.05).

A decrease in distances between the cranial and caudal borders of the anesthetized thoracic surface area was observed along the topographic lines when moving from the spine to the sternum (Figure 2). 
Table 2: Sensory block along different planes using three different LA volumes

\begin{tabular}{lccc}
\multicolumn{1}{c}{ Line } & $\begin{array}{c}\text { Group } \mathbf{1} \\
\text { Paravertebral }\end{array}$ & $\begin{array}{c}\text { Group } \mathbf{2} \\
\mathbf{2 . 0} \mathbf{~ t o ~} \mathbf{3 . 0} \mathbf{~ m L}\end{array}$ & $\begin{array}{c}\text { Group } \mathbf{3} \\
\mathbf{1 . 5} \mathbf{~ m L}\end{array}$ \\
\hline Scapular & $22.5(18.8$ "- 23.3) & $22.0(20.0-24.5)$ & $21.5(19.0-23.8)$ \\
\hline Posterior Axillary & $19.5(16.8-22.0)$ & $21.0(17.0-22.3)$ & $19.5(17.0-21.0)$ \\
\hline Midaxillary & $15.0(13.8-16.0)$ & $15.0(13.7-16.0)$ & $14.5(12.3-15.0)$ \\
\hline Midclavicular & $13.0(11.0-15.0)$ & $14.0(13.0-15.0)$ & $12.5(10.0-15.0)$ \\
\hline Sternal & $6.5(6.8-9.0)$ & $7.0(6.0-8.3)$ & $5.5(4.0-7.8)$ \\
\hline
\end{tabular}

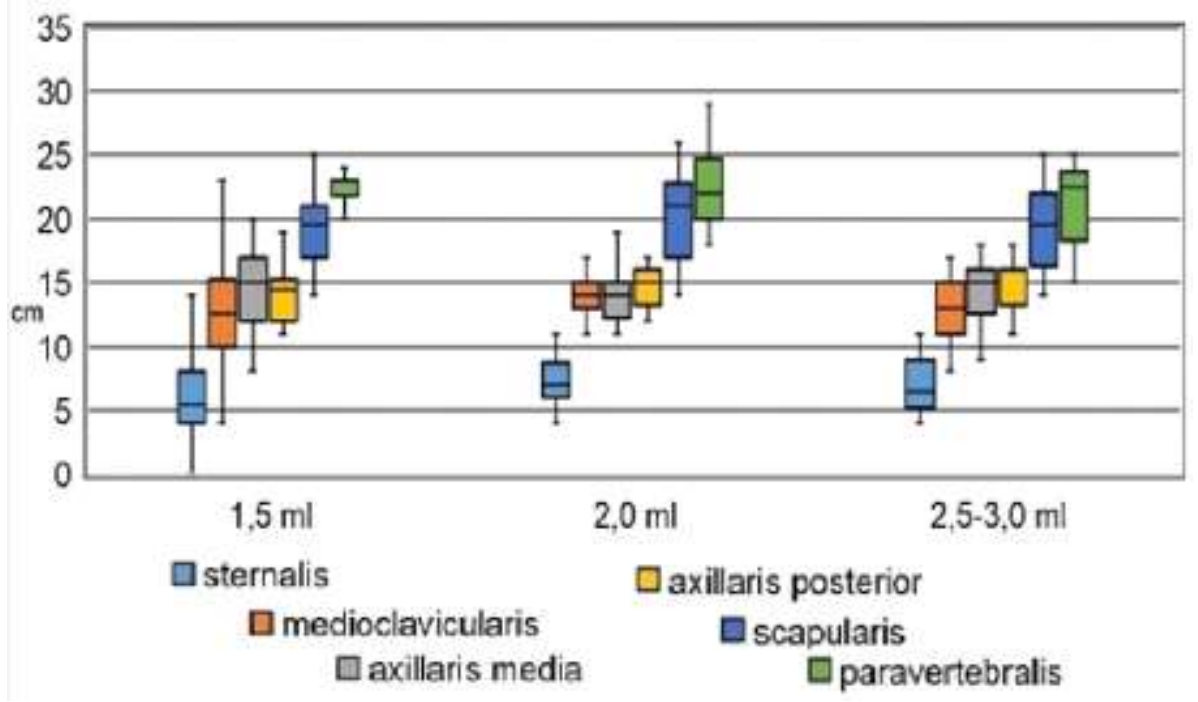

Figure 2: Distances between the borders identified along the topographic lines $(\mathbf{c m})$

Considering the data obtained, to determine which topographic thoracic lines showed statistically significant differences in distances, we performed the pair-wise comparison of the distances along all six lines. For statistical analysis, Wilcoxon test was used. To account for multiple comparisons, the significance level $\mathrm{p}$ for multiple pair-wise comparisons was recalculated (Bonferroni correction, statistical significance level adopted $\mathrm{p}=0.003$ ).

The distances along the sternal line were statistically significantly different from those along all other topographic lines in all three groups $(p<0.003)$. The distances along the midclavicular line did not differ from those along the midaxillary and posterior axillary lines $(\mathrm{p}>0.003)$, unlike those along the scapular and paravertebral lines $(\mathrm{p}$ $<$ 0.003). The distances along the midaxillary and posterior axillary lines did not differ from each other ( $p>0.003)$, but they statistically significantly differed from the distances along the sternal, scapular, and paravertebral lines ( $\mathrm{p}$ $<0.003$ ) in Groups 1 and 2. In Group 3, the distances along the posterior axillary and scapular lines showed no significant difference ( $p>0.003)$. The distances alond the scapular and paravertebral lines were similar in all three groups $(\mathrm{p}>0.003)$.

Thus, the measured distances between the identified borders were different for topographic lines in question. A decrease in these distances was seen when moving from the spine to the sternum.

The pair-wise comparison of the distances along the topographic thoracic lines in the groups is shown in Table 3. 
We studied whether the side of the block might have an impact on the area of the sensory block. Using the Mann-Whitney test, the distances observed on the left and right sides of the thorax were compared. For all topographic lines, no differences were found $(\mathrm{p}>0.05)$.

Table 3: Pair-wise comparison of the distances along the topographic lines in Groups 1, 2, and 3

\begin{tabular}{|c|c|c|c|}
\hline & & ou & \\
\hline Line vs. Line & 1 & 2 & 3 \\
\hline $\begin{array}{l}\text { Sternal line vs. Midclavicular } \\
\text { line }\end{array}$ & \# & \# & \# \\
\hline Sternal line vs. Midaxillary line & \# & \# & \# \\
\hline $\begin{array}{l}\text { Sternal line vs. Posterior } \\
\text { axillary lines }\end{array}$ & \# & \# & \# \\
\hline Sternal line vs. Scapular line & \# & \# & \# \\
\hline $\begin{array}{l}\text { Sternal line vs. Paravertebral } \\
\text { line }\end{array}$ & \# & \# & \# \\
\hline $\begin{array}{l}\text { Midclavicular line } \\
\text { Midaxillary line }\end{array}$ & * & * & * \\
\hline $\begin{array}{l}\text { Midclavicular line vs. Posterior } \\
\text { axillary lines }\end{array}$ & * & * & * \\
\hline $\begin{array}{l}\text { Midclavicular line vs. Scapular } \\
\text { line }\end{array}$ & \# & \# & \# \\
\hline $\begin{array}{l}\text { Midclavicular line vs. } \\
\text { Paravertebral line }\end{array}$ & \# & \# & \# \\
\hline $\begin{array}{l}\text { Midaxillary line vs. Posterior } \\
\text { axillary lines }\end{array}$ & * & * & * \\
\hline $\begin{array}{l}\text { Midaxillary line vs. Scapular } \\
\text { line }\end{array}$ & \# & \# & \# \\
\hline $\begin{array}{l}\text { Midaxillary line } \\
\text { Paravertebral line }\end{array}$ & \# & \# & \# \\
\hline $\begin{array}{l}\text { Posterior axillary lines vs. } \\
\text { Scapular line }\end{array}$ & \# & \# & * \\
\hline $\begin{array}{l}\text { Posterior axillary lines vs. } \\
\text { Paravertebral line }\end{array}$ & \# & \# & \# \\
\hline $\begin{array}{l}\text { Scapular line } \\
\text { Paravertebral line }\end{array}$ & * & * & * \\
\hline
\end{tabular}

Legend: \# Statisticaly significant difference, $p<0.003$

* No significant difference, $p>0.003$

The groups with different LA volumes used for PVB showed no differences in the distances along the same topographic thoracic lines (Kruskal-Wallis test, $\mathrm{p}>0.05$ ).

Thoracic PVB with 2.5 to $3.0 \mathrm{~mL}, 2.0 \mathrm{~mL}$, or $1.5 \mathrm{~mL}$ of $0.75 \%$ ropivacaine solution per nerve (T1 to T6) did not affect the sensory block distribution on the thoracic surface along the topographic lines studied. Thus, an effective block can be achieved using less than $3.0 \mathrm{ml}$ of $0.75 \%$ ropivacaine solution per nerve.

\section{DISCUSSION}

We performed multi-injection thoracic PVB using 1.5 to $3.0 \mathrm{~mL}$ of anesthetic to block one spinal nerve. We were first to study and describe the effect of low volumes of LA on paravertebral block distribution on the thoracic surface. The study showed that a decrease in the distances between the cranial and caudal borders of the anesthetized thoracic surface area was observed along the topographic lines when moving from the spine to the sternum. Following the spinal nerve block (T1 to T6), the measured nerve block lengths were as follows: 21.5 to $22.5 \mathrm{~cm}$ along the paravertebral line, 19.5 to $21.0 \mathrm{~cm}$ along the scapular line, 14.5 to $16.0 \mathrm{~cm}$ along the posterior axillary line, 14.0 to $15.0 \mathrm{~cm}$ along the midaxillary line, 12.5 to 14.0 $\mathrm{cm}$ along the midclavicular line, and 5.5 to 7.0 $\mathrm{cm}$ along the sternal line. Moreover, the three patient groups that received 2.5 to $3.0 \mathrm{~mL}$, $2.0 \mathrm{~mL}$, or $1.5 \mathrm{~mL}$ of LA per one nerve did not differ in the areas of loss of pain sensation on the thoracic surface along the same topographic lines. The results do not support the general notion of the innervation of the corresponding "strip" of skin from the posterior median line to the anterior median line (dermatome) by a spinal nerve as well as a minimum innervation overlap on the anterior surface of the thorax. ${ }^{9}$

Analysis of PubMed publications is given below. Cheema et al. found that a $15 \mathrm{ml}$ bolus of LA for PVB resulted in a block of an average of five dermatomes, one dermatome above and four dermatomes below the injection site. However, the number of dermatomes anesthetized can vary significantly (one to eight dermatomes). ${ }^{10}$ 
Anatomists have long sought to prove the existence of thoracic plexus, ${ }^{11}$ similar to the cervical plexus, brachial plexus, lumbar plexus, and sacral plexus. The notion of thoracic plexus fills in a logical "gap" between the brachial and lumbar plexuses. However, anatomical studies did not give a definitive answer for anesthesiologists as to the features of the afferent innervation achieved by the thoracic plexus. Apparently, for this reason, the data obtained by anatomists received no clinical interpretation. Special features of the thoracic cross-innervation affect the analgesia development after PVB. This can lead to an ineffective block. With that in mind, in our study, we determined the cranial and caudal borders of loss of pain sensation after multiinjection PVB performed at levels T1 to T6. The use of multi-injection PVB ensures a predictable block effect. Reduction in LA volume from $3.0 \mathrm{ml}$ to $1.5 \mathrm{ml}$ per nerve (T1 to T6) resulted in systemic toxicity prevention and ensured an effective block.

\section{CONCLUSION}

A decrease in the anesthetized surface area along the topographic lines studied was observed when moving from the spine to the sternum. However, different volumes of the local anesthetic solutions produced equivalent sensory along the same topographic thoracic lines. Hence, even less than $2 \mathrm{~mL}$ of local anesthetic per spinal nerve for paravertebral block may be adequate for breast surgery, provided block precision is enhanced with ultrasound guidance.

Conflict of interest: Nil declared by the authors.

\section{Authors' contribution:}

VY: concept, conduction of the study work, processing results, conclusions, writing an article

AM: concept, discussion of results, conclusions, manuscript editing

\section{REFERENCES}

1. Krediet AC, Moayeri N, van Geffen GJ, Bruhn J, Renes S, Bigeleisen $\mathrm{PE}$, et al. Different approaches to ultrasound-guided thoracic paravertebral block. Anesthesiology. 2015;123(2):45974. [PubMed] DOl: 10.1097/ALN.0000000000000747

2. Woodworth GE, Ivie RM, Nelson $\mathrm{SM}$, et al. Perioperative Breast Analgesia: A qualitative review of anatomy and regional techniques. Reg Anesth Pain Med. 2017 Sep/Oct;42(5):609-31. [PubMed] DOI: 10.1097/AAP.0000000000000641

3. Marhofer $D$, Marhofer $P$, Kettner SC, Fleischmann E, Prayer D, Schernthaner M, et al. Magnetic resonance imaging analysis of the spread of local anesthetic solution after ultrasound-guided lateral thoracic paravertebral blockade: a volunteer study. Anesthesiology. 2013;118(5): 1106-12.

[PubMed] DOI: $\underline{\text { 10.1097/ALN.0b013e318289465f }}$
4. Fujii T, Shibata Y., Nishiwaki K. Observation of ultrasound-guided thoracic paravertebral block using thoracoscopy. Acta Anaesth Taiwanica. 2016;54(3):101-2. [PubMed] DOI: 10.1016/.aat.2016.05.004

5. Joshi R, Singh MK, Bhattacharjee $S$, Tobin R, Kaur D, Singh SK. Ultrasound guided paravertebral block vs. modified PECS block for modified radical mastectomy. Anaesth. Pain Intensive Care. 2019;23(2):172-7. [Free Full Text]

6. Schnabel A, Reichl SU, Kranke P, Pogatzki-Zahn EM, Zahn PK. Efficacy and safety of paravertebral blocks in breast surgery: a meta-

7. analysis of randomized controlled trials. $\mathrm{Br} \mathrm{J}$ Anaesth. 2010;105(6):842-52. [PubMed] DOI: $10.1093 / \mathrm{bja} /$ aeq265

8. Naja Z, Lönnqvist PA. Somatic paravertebral nerve blockade Incidence of failed block and complications.

Anaesthesia.2011;56(12):1181201. [PubMed] DOI: $10.1046 /$ /.13652044.2001.02084-2.x
9. Chen $N$, Qiao $Q$, Chen $R, X u Q$, Zhang $Y$, Tian $Y$. The effect of ultrasound-guided intercostal nerve block, single-injection erector spinae plane block and multipleinjection paravertebral block on postoperative analgesia in thoracoscopic surgery: a randomized, double-blinded, clinical trial. J Clin Anesth. 2019;59:106111. [PubMed] DOI: 10.1016/j.jclinane.2019.07.002

10. Mancall EL, Brock DG. Gray's Clinical Neuroanatomy: the anatomic basis for clinical neuroscience. Philadelphia, PA: Saunders; 2011. p 117-25.

11. Cheema SP, Ilsley D, Richardson J, Sabanathan S. A thermographic study of paravertebral analgesia. Anaesthesia. 1995;50(2):118-21. [PubMed] DOI: 10.1111/j.13652044.1995.tb15092.x

12. Lobko PI, Rombalskaya AR. Do strict segment associations exist between peripheral nervea, internal organs and central nervous system? Healthcare. 2011;5:46-51.. 